\section{BMJ Paediatrics Open}

\title{
Retrospective audit of guidelines for investigation and treatment of bronchiolitis: a French perspective
}

Myriam Benhamida, Tiphaine Bihouee, Marie Verstraete, Christèle Gras Le Guen, Elise Launay

To cite: Benhamida M, Bihouee T, Verstraete M, et al. Retrospective audit of guidelines for investigation and treatment of bronchiolitis: a French perspective. BMJ Paediatrics Open 2017;1:e000089. doi:10.1136/ bmjpo-2017-000089

- Additional material is published online only. To view please visit the journal online (http://dx.doi.org/10.1136/ bmjpo-2017-000089).

\section{The results of this study} were presented at the annual meeting of the French Pediatric Society in May 2016 in Lille (France).

Received 21 May 2017 Revised 8 September 2017 Accepted 11 September 2017

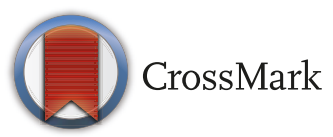

Clinique Médicale de Pédiatrie, Hôpital Mère Enfant, Centre Hospitalier Universitaire Nantes, Nantes, France

Correspondence to Dr Myriam Benhamida; myriam. benhamida@chu-nantes.fr

\section{ABSTRACT}

Introduction As the most recent French bronchiolitis guidelines were published in 2000, there is a current overinvestigation and an overtreatment of infants hospitalised with bronchiolitis in France. In 2012, the Group of Pediatric University Hospitals in Western France ('HUGO') proposed new evidence-based clinical practice guidelines in keeping with the latest international guidelines. We hypothesise that the implementation of these guidelines contributed to the quality improvement of the management of bronchiolitis in our hospital. The aim of this study was to determine the impact of these guidelines on the management of bronchiolitis inpatients.

Methods This retrospective before/after study design was conducted in the general paediatric unit of a tertiary care French hospital, looking at 1 year before (ie, the winter of 2011-2012) and 1 year after (ie, the winter of 20132014) the implementation of the guidelines. Two hundred and eighty bronchiolitis inpatients, all less than 1 year of age, 115 in 2011-2012 and 165 in 2013-2014, were included. The primary outcome we sought to evaluate was the proportion of children administered a diagnostic test associated with a treatment not routinely recommended by the guidelines. As balancing measures, we evaluated the length of stay, the intensive care unit transfer and the readmission rates.

Results Following implementation of the guidelines, use of any given treatment associated with a diagnostic test was reduced by $66 \%(p<0.001)$. There were major decreases in the use of chest $X$-ray ( $86 \% v s 26 \%, p<0.001)$, antibiotics (38\%vs13\%, $\mathrm{p}<0.001)$ and corticosteroids (10\%vs $3 \%, p=0.011)$. Balancing measures were not significantly different.

Conclusions HUGO guidelines were effective at reducing the administration of unnecessary diagnostic tests and medications. This study was the first step in convincing French paediatricians to streamline their practices until updated national guidelines are published.

\section{INTRODUCTION}

Acute viral bronchiolitis results in 30000 hospitalisations annually in France. ${ }^{1}$ In 2014 and 2015, the National Institute for Health and Care Excellence (NICE), ${ }^{2}$ the American Academy of Pediatrics (AAP) ${ }^{3}$ and the Canadian Paediatric Society (CPS), ${ }^{4}$ recommended

\section{What is already known on this topic?}

Bronchiolitis results in 30000 hospitalisations annually in France.

- There is a current overuse of diagnostic and therapeutic resources in the management of bronchiolitis inpatient treatment in France.

- The Group of Pediatric University Hospitals in Western France (HUGO) guidelines on bronchiolitis were published in 2012.

\section{What this study hopes to add?}

- The implementation of HUGO guidelines allowed the curtailment of excessive use of chest X-rays, respiratory syncytial virus testing and inflammatory blood tests.

- Reducing the administration of unnecessary treatments such as corticosteroids, salbutamol and chest physiotherapy on a French population of bronchiolitis inpatients is possible.

curtailing the excessive use of antibiotics, chest X-rays (CXR), respiratory syncytial virus (RSV) testing, inflammatory blood test, as well as unnecessary treatments such as the administration of corticosteroids, salbutamol and chest physiotherapy. However, the most recent French guidelines date from 2000. ${ }^{5}$ This has led to a current overinvestigation and overtreatment of infants hospitalised with bronchiolitis in our country. Thus, in two recent French studies, ${ }^{67}$ the rates of CXR, RSV testing and inflammatory blood testing performed were between $59 \%$ and $97 \%$, between $89 \%$ and $98 \%$ and around $57 \%$, respectively. In the study of Arnoux et al, ${ }^{7}$ the rate of chest physiotherapy was observed to be as high as $75 \%$. Moreover, in 2013, Gajdos et al ${ }^{8}$ reported a $14 \%$ rate for salbutamol use, $10 \%$ for corticosteroids and 28\% for antibiotics. By comparison, Ralston et at have proposed achievable benchmarks of cares (ABCs) for 
inpatient care in bronchiolitis: a $10 \%-19 \%$ rate of use for bronchodilators, a $0 \%-9 \%$ rate of use for corticosteroids, a $17 \%-19 \%$ rate of use for antibiotics and a $31 \%-42 \%$ rate of use for CXR. Furthermore, in a 2010 study conducted in 17 American hospitals, the rate of chest physiotherapy was $4 \% .{ }^{10}$ In addition, the rate of antibiotics use and RSV testing were $10 \%$ and $29 \%$, respectively, in the study by Akenroye $e t a l .{ }^{11}$

In order to improve bronchiolitis inpatient management, the Group of Paediatric University Hospitals in Western France ('HUGO') published guidelines in $2012^{12}$ that are in accord with the latest international recommendations. In this study, we sought to determine the impact of these HUGO guidelines. Our primary aim was to evaluate whether the streamlining of practices could be implemented in France. We hypothesised that an improvement in practices, that is, that the proportion of patients receiving treatments such as antibiotics, corticosteroids or salbutamol, and a diagnostic test such as CXRs, RSV testing or a blood test would be reduced following implementation of the HUGO guidelines. As secondary outcomes, we evaluated the length of stay (LOS), hospitalisation costs and rates of intensive care unit (ICU) transfer and readmission at 7 days. We also compared the modalities of supportive care prior to and following the implementation of the guidelines.

\section{METHODS}

\section{Setting and study design}

The Nantes University Hospital (NUH) provides paediatric care for a geographic area with a population of 850000 with 12107 births as of 2010. Each winter, bronchiolitis accounts for approximately 500 hospitalisations at the NUH. ${ }^{13}$ We conducted a retrospective study of quality improvement intervention in order to standardise the care provided to bronchiolitis inpatients. We compared the year prior to implementation of the HUGO guidelines (ie, the winter of 2011-2012) to the year following their implementation (ie, the winter of 2013-2014). We deemed the winter of 2012-2013 to be a transition year.

For each bronchiolitis season, we analysed the 3 weeks of major bronchiolitis epidemics. Each year, during those weeks, the NUH general paediatric unit becomes overcrowded, accommodating practically only bronchiolitis inpatients. We hypothesised that the workload is similar year-over-year during those periods. According to the regional office of the French Institute for Public Health of the Pays de la Loire, for the winter of 2011-2012, the three major bronchiolitis epidemic weeks were weeks 48 , 49 and 50. For the winter of 2013-2014, they were weeks 51,52 and 1 .

The project was approved by the institutional review board at the NUH.

French legislation stipulates that informed consent is not required, and local retrospective data may be used for an epidemiological study.
This study was reported according to the Standards for Quality Improvement Reporting Excellence (SQUIRE) reporting guidelines. ${ }^{14}$ Intervention: HUGO Bronchiolitis Guidelines Development and Implementation

In 2011, paediatricians, paediatric pulmonologists and emergency physicians belonging to HUGO met to analyse the recent published data regarding bronchiolitis in children less than 1 year of age. Criteria to distinguish childhood asthma from acute viral bronchiolitis were established (see onlinesupplementary file 1). Prescriptions of diagnostic tests, antibiotics and chest physiotherapy were defined and reserved for limited situations. Modalities of oxygen supplementation and nutritional support were proposed. All these recommendations were summarised in the HUGO bronchiolitis guidelines () see online supplementary file 1$){ }^{12}$

The guidelines were implemented by the NUH in September 2012 by holding team meetings involving paediatric nurses, physicians and trainees. These interprofessional meetings occur annually at the start of bronchiolitis season. Daily brief meetings (just following the usual morning meeting) with physicians and nurses were also organised during the 14 first days of the epidemic seasons to discuss difficulties, and a summary of the guidelines was posted in the emergency and the general paediatric wards. The guidelines were integrated into the NUH guidelines book, and they are readily accessible online via the hospital's intranet website.

\section{Study population and data sources}

The target population for the HUGO bronchiolitis guidelines was children from birth to 1 year of age, who were diagnosed with bronchiolitis. The diagnosis of bronchiolitis was based on their medical history and a physical examination showing viral upper respiratory tract prodrome, followed by increased respiratory effort and wheezing, as recommended in the HUGO and international guidelines. ${ }^{2-4} 12$ The cut-off age of 1year was decided according to the current literature. ${ }^{115-17}$

Using the NUH Medical Program of Information System (PMSI), we screened for all patients with a bronchiolitis diagnosis defined by the group of codes 'Acute Bronchiolitis' of the International Classification of Disease 10 (J21, J21.0, J21.8 and J21.9) and who were hospitalised in the general paediatric unit of the NUH during the inclusion periods. Of these patients, we excluded patients aged $>12$ months old and patients with a history of more than one wheezing dyspnoea episode and obvious mistakes in the PMSI such as an absence of any clinical signs of respiratory infection in their medical files.

We opted for a pragmatic study, so we did not exclude patients with comorbidities or those who had required a transfer to the ICU at any time during their management. Only the patient's management in the general paediatric unit was evaluated.

Data were collected by the retrospective review of medical files in October 2014, ${ }^{1}$ tabulated using Excel 
(Microsoft, Redmond, Washington, USA). Data on the cost of services were obtained from the hospital's administrative and financial databases for each included patient.

\section{Methods of evaluation}

To capture the overall impact of the HUGO guidelines, we used a composite outcome build with the two main resources that tend to be misused in bronchiolitis: diagnostic tests and treatments. Our primary outcome was the proportion of patients having been administered at least one antibiotic, corticosteroid or salbutamol treatment, and either a CXR, RSV testing or an inflammatory blood test. We selected these treatments and tests because their uses are not routinely recommended by the HUGO guidelines. Moreover, they are typical outcomes used to evaluate unnecessary treatments in bronchiolitis quality improvement studies. ${ }^{911} 1819$

As secondary outcomes, we compared total hospitalisation costs (including the cost of overall unit functioning, laboratory tests, imaging, drugs, supplies and materials), the use of each treatment and diagnostic test: antibiotics, salbutamol (>1 dose), corticosteroids, chest physiotherapy, CXR, RSV testing and inflammatory blood tests. Inflammatory blood tests included determination of $\mathrm{C}$ reactive protein (CRP) levels and/or full blood counts and/or procalcitonin levels.

To evaluate whether the HUGO guidelines affected the provision of supportive treatments, we assessed the duration and the level of oxygen supplementation, as well as the duration and the type of fluid replacement. The guidelines suggest limiting continuous pulse oxymetry, decreasing oxyhaemoglobin saturation targets, especially during sleep, and nasogastric feeding is preferred, with the exception of severe bronchiolitis in patients with a WANG score $>8$. Based on the nature of French bacterial ecology, especially for Haemophilus influenzae, the HUGO guidelines recommend choosing amoxicillin in case of a concomitant bacterial infection. We therefore evaluated the type of antibiotic that was prescribed. Balancing measures to observe unintended consequences of the guidelines were: LOS, ICU transfer, readmission at 7 days and mortality rates.

\section{Statistical analyses}

The sample size was calculated on the basis of an expected reduction postguidelines implementation of $40 \%$ of the primary outcome, as published previously in other studies. ${ }^{11920}$ Assuming a power of $80 \%$, $\alpha$ of 0.05 and a two-tailed test, the estimated sample size was 111 patients per period. This size was compatible with the approximately 150 bronchiolitis hospitalisations at the NUH during the three bronchiolitis epidemic weeks. ${ }^{13}$

Continuous variables were expressed as medians and IQRs if their distribution was abnormal, and the MannWhitney test was used. If the distribution was normal, means, SD and the t-test were used. Categorical factors were expressed as percentages, and they were compared using the $\chi^{2}$ tests. The Fisher's test was used if the expected numbers were $<5$.

Cost savings following implementation of the guidelines were obtained by determining the difference between the mean cost per patient in 2011 and in 2013, and the SE of the difference in these means. Statistical analyses were performed using STATISTICA V.10 software (data analysis software system).

\section{RESULTS}

During the inclusion periods, there were 638 emergency consultations for bronchiolitis followed by 376 hospitalisations at the NUH. Of these patients, 311 were assessed for eligibility for the study, and 280 patients were enrolled: 115 patients for period 1 (ie, the winter of 2011-2012) and 165 patients for period 2 (ie, the winter of 20132014) (figure 1). Twenty-four children had comorbidities (see online supplementary file 2). The hospitalisation rate following emergency consultation for bronchiolitis was higher in the winter of 2013-2014 than in the winter of 2011-2012 $(\mathrm{p}<0.001)$. There was no significant difference in the proportion of initial hospitalisations in the ICU for bronchiolitis between the two periods $(\mathrm{p}=0.14)$. There were no significant differences between period 1 and period 2 group characteristics, except in terms of the history of prematurity $<37 \mathrm{SA}$ (table 1 ).

\section{Primary outcome}

One year after implementation of the HUGO guidelines, the proportion of patients having at least one treatment in conjunction with any of the tests was significantly reduced by two-thirds (table 2 ).

\section{Secondary outcomes}

In period 2, we noticed significant reductions in the use of CXRs and inflammatory blood tests, as well as antibiotic and corticosteroids use. Downward trends for RSV testing and oxygen supplementation were also observed (table 2). Following implementation of the guidelines, the prescription of amoxicillin-clavulanic acid declined, whereas prescription of amoxicillin increased significantly. The use of chest physiotherapy, already minor in period 1 , was nearly absent in period 2 . There was a switch from intravenous to nasogastric fluid administration between periods 1 and 2. The durations of intravenous or nasogastric fluid replacement were not different prior to and following implementation of the HUGO guidelines.

In the subgroup analysis excluding patients with a history of prematurity (see online supplementary file 3 ) and or those with comorbidities (see online supplementary file 4 , all of the differences that were statistically significant in the general outcomes analysis remained significant. The downward trends of intravenous and supplemental oxygen use became significant.

The mean total cost of hospitalisation per patient in the winter of 2011-2012 was $€ 1710.45$ and $€ 1656.40$ in 


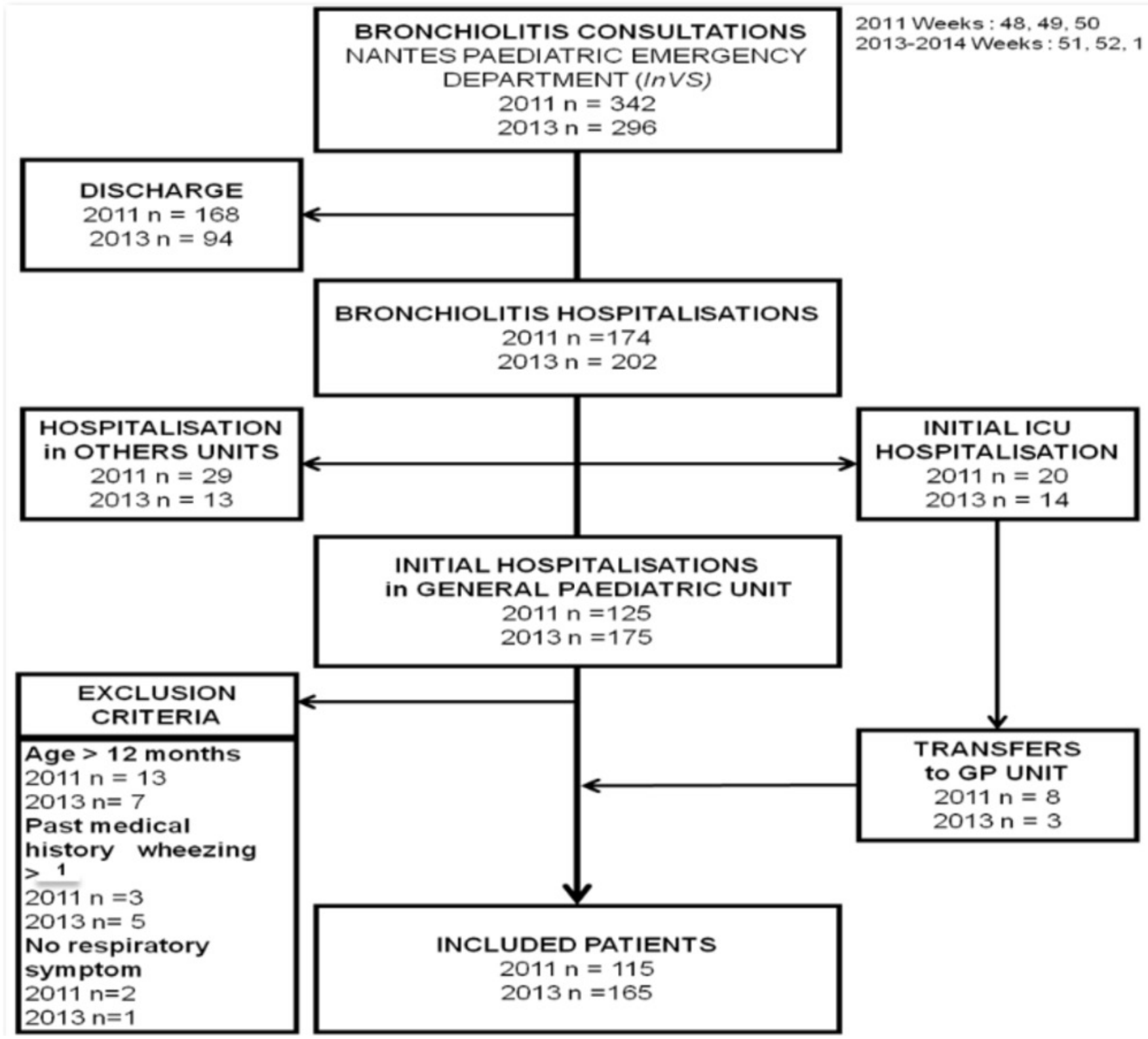

Figure 1 Study population flow diagram. GP unit, general paediatric unit; ICU, intensive care unit; InVs, French Institut for Public Health

the winter of 2013-2014. There were statistically significant decreases in the mean laboratory costs and in the mean imaging costs between periods 1 and 2 (table 3 ).

We found no difference in the rates of balancing measures after implementation of the guidelines. The median LOS was 2.0 days with an IQR of 1.5-3.0 days in periods 1 and $2(\mathrm{p}=0.28)$. The ICU transfer rate was $7 \%$ in the winter of $2011-2012$ and $4.2 \%$ in the winter of 2013-2014 $(p=0.23)$. The readmission rate at 7 days for all causes was $4.4 \%$ prior to implementation of the

\begin{tabular}{llll}
\hline Table 1 Baseline patient characteristics & & & \\
\hline & $\mathbf{2 0 1 1}(\mathbf{n = 1 1 5})$ & $\mathbf{2 0 1 3}(\mathbf{n = 1 6 5 )}$ & $\mathbf{p ~ V a l u e ~}$ \\
\hline Age, months, mean \pm SD & $2.70 \pm 2.57$ & $2.17 \pm 2.23$ & 0.07 \\
Gender, male $(\mathrm{n}(\%))$ & $64 / 115(56)$ & $89 / 165(54)$ & 0.78 \\
History of wheezing $(\mathrm{n}(\%))$ & $12 / 115(10)$ & $15 / 165(9.1)$ & 0.71 \\
Comorbidity (n (\%)) & $13 / 115(11)$ & $11 / 165(6.7)$ & 0.17 \\
Prematurity $<37$ weeks of gestation $(\mathrm{n}(\%))$ & $14 / 115(12)$ & $8 / 165(4.9)$ & 0.03 \\
\hline
\end{tabular}


Table 2 Outcomes pre-HUGO and post-HUGO guideline implementation

\begin{tabular}{|c|c|c|c|}
\hline & $2011(n=115)$ & $2013(n=165)$ & p Value \\
\hline $\begin{array}{l}\text { Treatment* and } \\
\text { test† }(\mathrm{n}(\%))\end{array}$ & $52 / 115(45)$ & 25/165 (15) & $<0.001$ \\
\hline $\begin{array}{l}\text { At least one } \\
\text { treatment }^{\star}(\mathrm{n}(\%))\end{array}$ & $52 / 115(45)$ & 46/165 (28) & 0.003 \\
\hline $\begin{array}{l}\text { At least one } \\
\text { test† (n (\%)) }\end{array}$ & 101/115 (88) & $52 / 165$ (32) & $<0.001$ \\
\hline CXR (n (\%)) & 99/115 (86) & 44/165 (27) & $<0.001$ \\
\hline $\begin{array}{l}\text { RSV nasopharyngeal } \\
\text { swabs (n (\%)) }\end{array}$ & 28/115 (24) & 26/165 (16) & 0.073 \\
\hline $\begin{array}{l}\text { Inflammatory blood } \\
\text { test }(\mathrm{n}(\%))\end{array}$ & $34 / 115(30)$ & 18/165 (11) & $<0.001$ \\
\hline Antibiotic use (n (\%)) & 44/115 (38) & 22/165 (13) & $<0.001$ \\
\hline $\begin{array}{l}\text { Salbutamol use }>1 \\
\text { dose }(\mathrm{n}(\%))\end{array}$ & 9/115 (8.0) & 8/165 (5.0) & 0.21 \\
\hline $\begin{array}{l}\text { Corticosteroid } \\
\text { use }(n(\%))\end{array}$ & $12 / 115(10)$ & $5 / 165$ (3.0) & 0.011 \\
\hline $\begin{array}{l}\text { Chest } \\
\text { physiotherapy (n (\%)) }\end{array}$ & $7 / 115(6.1)$ & 1/165 (0.6) & 0.009 \\
\hline $\begin{array}{l}\text { Nasogastric fluid } \\
\text { replacement (n (\%)) }\end{array}$ & $19 / 115(17)$ & $58 / 165$ (35) & $<0.001$ \\
\hline $\begin{array}{l}\text { Nasogastric feed } \\
\text { length, day, median } \\
(\mathrm{IQR})\end{array}$ & $1.5(1.0-3.0)$ & $2.0(1.0-3.0)$ & 0.70 \\
\hline $\begin{array}{l}\text { Intravenous fluid } \\
\text { replacement (n (\%)) }\end{array}$ & 25/115 (22) & 22/165 (13) & 0.064 \\
\hline $\begin{array}{l}\text { Intravenous hydration } \\
\text { length, day, median } \\
\text { (IQR) }\end{array}$ & $1.0(1.0-1.5)$ & $1.5(0.5-2.0)$ & 0.59 \\
\hline Oxygen use (n (\%)) & $71 / 115$ (62) & $83 / 165(50)$ & 0.058 \\
\hline $\begin{array}{l}\mathrm{O}_{2} \max , \mathrm{L} / \mathrm{min} \text {, } \\
\text { median }(\mathrm{IQR})\end{array}$ & $0.5(0.25-1)$ & $0.5(0.5-1)$ & 0.67 \\
\hline $\begin{array}{l}\text { Oxygen duration, } \\
\text { day, median (IQR) }\end{array}$ & $2.0(1.0-2.5)$ & $2.0(1.5-3.0)$ & 0.10 \\
\hline $\begin{array}{l}\% \text { Amoxicillin in } \\
\text { ATB }(n(\%))\end{array}$ & 9/44 (20) & 19/22 (86) & $<0.001$ \\
\hline $\begin{array}{l}\% \text { Amoxicillin- } \\
\text { clavulanate in } \\
\text { ATB }(n(\%))\end{array}$ & $28 / 44(64)$ & $1 / 22(4.5)$ & $<0.001$ \\
\hline $\begin{array}{l}\text { LOS in general } \\
\text { paediatric wards, } \\
\text { day, median (IQR) }\end{array}$ & $2.0(1.5-3.0)$ & $2.0(1.5-3.0)$ & 0.28 \\
\hline ICU transfer (n (\%)) & $8 / 115(7)$ & 7/165 (4.2) & 0.23 \\
\hline $\begin{array}{l}\text { All-cause 7-day } \\
\text { readmission (n (\%)) }\end{array}$ & 5/115 (4.4) & $7 / 156$ (4.2) & 0.59 \\
\hline
\end{tabular}

*Treatment among antibiotics/salbutamol/corticosteroids. †Test among CXR/blood test/RSV test.

ATB, antibiotic prescription; CXR, chest X-ray; ICU, intensive care unit; RSV, respiratory syncytial virus.

HUGO guidelines and $4.2 \%$ after their implementation $(\mathrm{p}=0.59) \quad$ (table 2$)$. There were no deaths during either period.
Table 3 Cost saving per patient postguideline implementation

\begin{tabular}{|c|c|c|}
\hline & $\begin{array}{l}\text { Mean cost saving } \\
\text { per patient, } €, \pm S D\end{array}$ & p Value \\
\hline Laboratory tests & $-26.12 \pm 7.80$ & 0.003 \\
\hline Imagery & $-17.77 \pm 2.63$ & $<0.001$ \\
\hline Material and supplies & $-28.03 \pm 16.99$ & 0.082 \\
\hline Drugs & $-14.15 \pm 12.19$ & 0.24 \\
\hline Global unit operating costs & $40.71 \pm 126.00$ & 0.80 \\
\hline
\end{tabular}

\section{DISCUSSION}

This work is the first French study showing that the standardisation of bronchiolitis inpatient management allowed for a reduction in unnecessary testing and treatments. One year after the implementation of these guidelines, we noticed significant reductions in the use of CXR, inflammatory blood tests, antibiotics, corticosteroids and chest physiotherapy, without a discernible increase in morbidity. Thus, the ABCs for inpatients care in bronchiolitis proposed by Ralston et al were reached. ${ }^{9}$

Even though our study was monocentric, the characteristics of our population are similar to those of other published studies, particularly three recent studies conducted in other French university hospitals. ${ }^{6-8}$ In the study of Carsin et $a l^{6}{ }^{6}$ the rates of nasopharyngeal viral swabs, inflammatory blood tests and intravenous fluid replacements were $98 \%, 57 \%$ and $54 \%$, respectively. Gajdos et $a l^{8}$ reported a $14 \%$ rate for salbutamol use, $10 \%$ for corticosteroids and $28 \%$ for antibiotics. The current overinvestigation and an overtreatment of infants hospitalised with bronchiolitis in France is not without potential for causing harm. Chest physiotherapy had no significant effect on time to recovery ${ }^{21}$ but increased the frequency of vomiting and transitory respiratory destabilisation in the work of Gadjos et al. ${ }^{8}$

There were no significant differences between the baseline characteristics of the two periods for the populations, except in terms of their history of prematurity. For this characteristic, the rate for period 1 of $12 \%$ was similar to the finding in other studies with rates between $8.7 \%$ and $16 \% .{ }^{617}$ However, this difference appeared to have a minor impact on our study's outcomes. Indeed, in the subgroup analysis that excluded patients with a history of prematurity, all of the statistically significant differences in the general outcomes analysis remained significant. This suggests that the observed improvement is due to the implementation of the guidelines rather than the changes in the typology of patients. We did not observe any significantly adverse effects of the HUGO bronchiolitis guidelines on mortality, ICU transfers or readmission rates at 7 days, but this could be due to the fact that our study lacked the power to adequately evaluate this. However, previously published studies involving larger populations that evaluated the impact of similar 
bronchiolitis guidelines did not report any deleterious effects on morbidity. ${ }^{11} 1819$

Concerning CXR, the NICE, ${ }^{2}$ the $\mathrm{AAP}^{3}$ and the CPS bronchiolitis guidelines ${ }^{4}$ reaffirm that current evidence does not support its routine use. It should be reserved for cases of ICU admission or signs of an airway complication such as pneumothorax. Indeed, the rate of differential diagnoses made thanks to CXR in bronchiolitis was between $0.4 \%$ and $0.8 \%$ in recent studies, ${ }^{62}$ whereas several studies suggest that CXR use increases the prescription of antibiotics. ${ }^{22-24}$ Schuh $e t a l^{22}$ showed the rate of infants identified for antibiotics preradiography was $2.6 \%$ and became $15 \%$ postradiography. Similarly, a French study showed $14 \%$ of the children without CXR received antibiotics versus $39 \%$ of those with CXR. ${ }^{23}$ Moreover, Carsin et al reported only 3.6\% of the routinely performed CXR changed bronchiolitis inpatient management ${ }^{6}$ almost all by antibiotic introduction.

Our results also suggest that reducing unnecessary care provided benefits in terms of LOS and was cost saving. AAP guidelines implementations were followed by reduction of the LOS from 2.3 to 1.8 days in Mittal's study ${ }^{19}$ and from 2.0 to 1.8 day in Ralston's study.$^{25}$ In our pragmatic study, the LOS remained stable at 2.0 days. However, it should be kept in mind that those studies excluded patients who had been transferred to the ICU or who had comorbidities. Moreover, in France, a national PMSI analysis of 29784 children hospitalised for bronchiolitis showed a median LOS of 3.0 days. ${ }^{1}$ Additionally, the mean LOS observed in the recent multicentric French trial on hypertonic saline nebulisation was 3.8 days. ${ }^{26}$ Moreover, the implementation of HUGO guidelines allowed for little cost savings of $€ 54.25$ per patient. By comparison, Akenroye et $a l^{1}$ reported a mean cost per patient reduced by $\$ 197$.

In regard to supportive care, the downward trend of supplemental oxygen use that was close to significance $(p=0.058)$. It could be improved by reassessing the oxygen discontinuation criteria and promoting intermittent pulse oximetry, as showed in two recent randomised trials. ${ }^{1627}$

In comparison with the results of other quality improvement studies, such as those reported in Ralston's systematic review, ${ }^{18}$ we encountered better reduction rates for unnecessary diagnostic tests and treatments. This level of success is probably linked to the design of our intervention, as it was a voluntary local collaborative work. A large team of NUH medical staff (eg, paediatricians, paediatric pulmonologists and emergency physicians) were involved in generating the HUGO guidelines and in their presentation in interprofessional team meetings. Having a large team engagement led by a site champion is one of the major determinants of success for a bronchiolitis quality improvement programme, as found by Ralston et al in their multicentric study. ${ }^{25}$ Moreover, the collaborative nature of the work helps to overcome clinical practice inertia and to promote evidence-based medicine. ${ }^{28}$
The main limitation of this study was its retrospective, monocentric before versus after design. In order to limit bias, we choose to evaluate the same unit during the three major bronchiolitis epidemic weeks. It may have introduced bias: performance during those times may be consistently better or worse than it might be at another time. However, the bias was the same for the two inclusion periods. We hypothesised that the workload is similar year-over-year during those busy weeks. There was no major change in the way the unit was run, senior medical staff or nurse teams between the two periods. We made the choice of a composite outcome associating treatment and diagnostic test; this outcome could appear heterogeneous. Nevertheless, treatment and diagnostic testing were the two main resources that tend to be misused in bronchiolitis. Having a composite outcome allowed us to capture the overall impact of the HUGO guidelines. Moreover, the use of each treatment and diagnostic test not routinely recommended by the guidelines were evaluated separately too, and we showed a clinically and statistically significant reduction of most of the inadequate tests or treatments.

In conclusion, we showed that reduction in the overuse of unnecessary diagnostic and therapeutic measure was possible in France. Sustainability and generalisability of the observed improvement are still to be evaluated. This study was a first step to convince the French paediatricians still reluctant to streamline their practices before the upcoming national French bronchiolitis guidelines.

Acknowledgements We would like to thank Arnaud Legrand for his statistical guidance, Noemie Fortin and Bruno Hubert from the French Institute for Public Health of the Pays de la Loire for their help with retrieving epidemiological data and Nathalie Surer and Marion Le Moal for their support of the PMSI extraction and the costs study. We are grateful to the patients and their families. We thank all of the physicians and nurses for their proper management of the medical files.

Contributors MB, CGLG, MV and EL designed the study. EL and CGLG supervised the study. MB was responsible for the data collection. MB and CGLG performed the data analysis. MB wrote the first draft of the manuscript. All authors interpreted the data, contributed to writing and revising the manuscript and take full responsibility for the integrity of the data and the accuracy of the data analysis.

\section{Competing interests None declared.}

Ethics approval The project was approved by the institutional review board at the Nantes University Hospital and was in accordance with the 1964 Declaration of Helsinki and its later amendments or comparable ethical standards. French legislation stipulates that informed consent is not required, and local retrospective data may be used for an epidemiological study.

Provenance and peer review Not commissioned; externally peer reviewed.

Data sharing statement Relevant anonymised data are available on reasonable request from the corresponding author.

Open Access This is an Open Access article distributed in accordance with the Creative Commons Attribution Non Commercial (CC BY-NC 4.0) license, which permits others to distribute, remix, adapt, build upon this work non-commercially, and license their derivative works on different terms, provided the original work is properly cited and the use is non-commercial. See: http://creativecommons.org/ licenses/by-nc/4.0/

(C) Article author(s) (or their employer(s) unless otherwise stated in the text of the article) 2017. All rights reserved. No commercial use is permitted unless otherwise expressly granted. 


\section{REFERENCES}

1. Che $D$, Caillère $N$, Josseran L. Surveillance et épidémiologie de la bronchiolite du nourrisson en France. Archives de Pédiatrie 2008;15:327-8.

2. Ricci V, Delgado Nunes V, Murphy MS, et al. Bronchiolitis in children: summary of NICE guidance. BMJ 2015;350:h2305.

3. Ralston SL, Lieberthal AS, Meissner HC, et al. Clinical practice guideline: the diagnosis, management, and prevention of bronchiolitis. Pediatrics 2014:134:e1474-e1502.

4 Friedman JN, Rieder MJ, Walton JM. Canadian paediatric society, acute aare committee, drug therapy and hazardous substances committee. Bronchiolitis: recommendations for diagnosis, monitoring and management of children one to 24 months of age. Paediatr Child Health 2014;19:485-91.

5 [Consensus conference on the management of infant bronchiolitis. Paris, France, 21 September 2000. Proceedings]. Arch Pédiatrie Organe Off Sociéte Fr Pédiatrie. In Press.;2001:8:1s-196.

6. Carsin A, Gorincour G, Bresson V, et al. La radiographie de thorax chez le nourrisson hospitalisé pour bronchiolite aiguë : réelle information ou simple irradiation ? Archives de Pédiatrie 2012;19:1308-15.

7. Arnoux V, Carsin A, Bosdure E, et al. Radiographie de thorax et bronchiolite aiguë : des indications en diminution ? Archives de Pédiatrie 2017;24:10-16.

8. Gajdos V, Katsahian S, Beydon N, et al. Effectiveness of chest physiotherapy in infants hospitalized with acute bronchiolitis: a multicenter, randomized, controlled trial. PLOS Med 2010;7:e1000345.

9. Ralston S, Parikh K, Goodman D. Benchmarking overuse of medical interventions for bronchiolitis. JAMA Pediatr 2015;169:805-6.

10 Ralston S, Garber M, Narang S, et al. Decreasing unnecessary utilization in acute bronchiolitis care: results from the value in inpatient pediatrics network. J Hosp Med 2013;8:25-30.

11. Akenroye AT, Baskin MN, Samnaliev M, et al. Impact of a bronchiolitis guideline on ED resource use and cost: a segmented time-series analysis. Pediatrics 2014;133:e227-e234.

12. Verstraete $M$, Cros $P$, Gouin $M$, et al. Prise en charge de la bronchiolite aiguë du nourrisson de moins de 1 an : actualisation et consensus médical au sein des hôpitaux universitaires du Grand Ouest (HUGO). Archives de Pédiatrie 2014;21:53-62.

13 Fortin N. Epidémies de bronchiolite dans l'agglomération nantaise 2007-2012: CIRE INVS de la Région Pays de la Loire.

14. Ogrinc G, Davies L, Goodman D, et al. SQUIRE 2.0 (Standards for quality improvement reporting excellence): revised publication guidelines from a detailed consensus process. BMJ Qual Saf 2016;25:986-92.

15. Meissner HC. Viral bronchiolitis in children. N Engl J Med 2016;374:62-72.

16. Cunningham S, Rodriguez A, Adams T, et al. Oxygen saturation targets in infants with bronchiolitis (BIDS): a double-blind, randomised, equivalence trial. Lancet 2015;386:1041-8.

17. Silver AH, Esteban-Cruciani N, Azzarone G, et al. 3\% Hypertonic saline versus normal saline in inpatient bronchiolitis: a randomized controlled trial. Pediatrics 2015;136:1036-43.

18. Ralston S, Comick A, Nichols $E$, et al. Effectiveness of quality improvement in hospitalization for bronchiolitis: a systematic review. Pediatrics 2014;134:571-81.

19. Mittal V, Darnell C, Walsh B, et al. Inpatient bronchiolitis guideline implementation and resource utilization. Pediatrics 2014;133:e73 0-e737.

20. Parikh K, Hall M, Teach SJ. Bronchiolitis management before and after the AAP guidelines. Pediatrics 2014;133:e1-e7.

21 Roqué iFM, Giné-Garriga M, Granados Rugeles C, et al. Chest physiotherapy for acute bronchiolitis in paediatric patients between 0 and 24 months old. Cochrane database of systematic reviews: John Wiley \& Sons, Ltd, 2016.

22. Schuh $\mathrm{S}$, Lalani $A$, Allen $U$, et al. Evaluation of the utility of radiography in acute bronchiolitis. J Pediatr 2007;150:429-33.

23. Ecochard-Dugelay E, Beliah M, Perreaux F, et al. Clinical predictors of radiographic abnormalities among infants with bronchiolitis in a paediatric emergency department. BMC Pediatr 2014;14:143.

24. Ecochard-Dugelay E, Beliah M, Boisson C, et al. Impact of chest radiography for children with lower respiratory tract infection: a propensity score approach. PLoS One 2014;9:e96189.

25. Ralston SL, Garber MD, Rice-Conboy E, et al. A multicenter collaborative to reduce unnecessary care in inpatient bronchiolitis. Pediatrics 2016;137:e20150851-9.

26 Angoulvant F, Bellêttre X, Milcent K, et al. Effect of nebulized hypertonic saline treatment in emergency departments on the hospitalization rate for acute bronchiolitis: a randomized clinical trial. JAMA Pediatr 2017;171:e171333.

27. McCulloh R, Koster M, Ralston S, et al. Use of intermittent vs continuous pulse oximetry for nonhypoxemic infants and young children hospitalized for bronchiolitis: a randomized clinical trial. JAMA Pediatr 2015;169:898-904.

28. Cabana MD, Rand CS, Powe NR, et al. Why don't physicians follow clinical practice guidelines? a framework for improvement. JAMA 1999;282:1458-65. 